\title{
Regulation of Flowering in Aquilegia
}

\author{
X. Zhang', J.W. White ${ }^{2}$, and D.J. Beattie ${ }^{3}$ \\ Department of Horticulture, The Pennsylvania State University, University Park, PA 16802
}

Additional index words. columbine, anthesis, defoliation, irradiance, SEM, flower initiation

Abstract. Aquilegia $\times$ hybrida Sims 'Purple' and 'Dove' initiated flower buds 5 months after seeding without being exposed to low temperatures. Four experiments were conducted to test the effects of gibberellic acid $\left(\mathbf{G A}_{3}\right)$, long photoperiod, long photoperiod with a high level of irradiance, and cold treatments on forcing of the two cultivars. Time from treatment to anthesis was reduced by 9 days for defoliated 'Purple' plants treated with 250 mg GA $/$ /iter, and by >14 days for defoliated 'Dove' plants treated with $125 \mathrm{mg} \mathrm{GA}$ /liter. Defoliated 'Purple' or 'Dove' plants treated with 18 hours of supplemental high pressure sodium (HPS) light at $250 \mathrm{\mu}] \mathrm{mol} \cdot \mathrm{m}^{-1} \cdot \mathrm{s}^{-2}(18 \mathrm{SH})$ reached anthesis 14 or 10 days earlier, respectively, after treatment than plants grown under natural daylight (Nat). The 18 SH treatment increased the number of flowers from eight and nine per plant on Nat plants for defoliated 'Dove' and 'Purple', respectively, to 16 flowers on $18 \mathrm{SH}$ plants. Cold treatments at $4 \pm \mathrm{IC}$ did not shorten the interval between treatment and anthesis, but decreased the number of flowers per plant in both cultivars. Chemical name used: gibberellic acid $\left(\mathbf{G A}_{3}\right)$.

Aquilegia, commonly known as columbine, is grown primarily as a perennial bedding plant. It is usually sown in late summer and flowers the following spring. Production as a pot plant or cut flower is limited mainly by its long production time, although the short shelf life of the individual flowers is also a limiting factor. Even in a greenhouse, it usually takes $\mathbf{7}$ to $\mathbf{8}$ months from seeding for Aquilegia to flower.

Literature on the flowering physiology of Aquilegia is scant. Shedron and Weiler (1982) reported that Aquilegia $\times$ hybrids required $\geq \$ 8$ weeks of vernalization for flowering, although some seedlings flowered without cold treatments regardless of photoperiod. They concluded that vernalization was probably the primary natural environmental factor required to induce flowering. They also reported that neither leaves nor light during vernalization was necessary for flower induction, apparently because the apical meristem, not the leaves, perceived the cold stimulus. $\mathrm{GA}_{3}$ induced some plants to flower but also caused weak stems, some of which collapsed before florets opened, especially at high concentrations (they used 25, 50, 75, and 100 $\mathrm{mg}$.liter ${ }^{-1}$ spray). However, the effects of long photoperiod with a high level of irradiance and the interaction effects among photoperiod, high irradiance, $\mathrm{GA}_{3}$, and cold treatments were not studied.

The objectives of this study were to examine the effects of high irradiance, long photoperiod, $\mathrm{GA}_{3}$ application, cold treatments, and the interactions among these factors on growth and flowering of Aquilegia $\times$ hybrida 'Purple' and 'Dove'.

\section{Materials and Methods}

\section{General methods}

Weddles' Songbird series of Aquilegia inbreds 'Dove' and 'Purple' were sown in Colorado in late July 1986 and shipped to Pennsylvania State University (PSU) on 12 Oct. 1986. Seedlings had been grown outdoors before shipment and had five to

Received for publication 10 Dec. 1990. Contribution no. 145, Dept. of Horticulture, The Pennsylvania State Univ. Authorized for publication as paper no. 8178 in the Journal Series of the Penn. Agr. Expt. Sta. The cost of publishing this paper was defrayed in part by the payment of page charges. Under postal regulations, this paper therefore must be hereby marked advertisement solely to indicate this fact.

'Graduate Assistant.

${ }^{2}$ Professor.

${ }^{3}$ Assistant Professor. six leaves per plant when received. They were then transplanted into 0.2-liter $(7.5 \mathrm{~cm})$ round plastic pots on 14 Oct. 1986 and grown in PSU greenhouses set at $21 \mathrm{C}$ day/16C night. The potting medium was a mixture of 16 vermiculite : 16 sphagnum peat: 10 soil (by volume) amended with $\left(\mathrm{g} \mathrm{m}^{-3}\right) 4260$ dolomitic lime, 341 superphosphate, 568 potassium nitrate, and 71 fritted trace elements (FTE no. 555, W.R. Grace, Cambridge, Mass.). Plants received Nat until treatments began and were fertilized at each irrigation with $200 \mathrm{mg}$ N/liter from Peters $15 \mathrm{~N}-3 \mathrm{P}-12 \mathrm{~K}$ fertilizer.

Four experiments were conducted: 'Purple' was used in Expts. 1 and 2 and 'Dove' in Expts. 3 and 4. In all experiments, plants were treated at the 15- to 16-leaf stage, which was 178 or 185 days from sowing for 'Dove' and 'Purple', respectively.

Starting in late November when most plants had 11 to 12 leaves, three plants of each cultivar were sampled weekly for SEM study to determine if flower initiation had occurred before treatments, so that the effects of cold and other treatments could be better defined.

For all experiments, the number of days from the first day of light treatment to appearance of VB and anthesis, plant height, number of inflorescences, and number of flowers per plant were recorded. Only those flowers that reached anthesis were counted in the number of flowers; aborted flower buds were excluded. Plant height was measured from pot rim to the receptacle of the first flower on the inflorescence when it reached anthesis.

\section{SEM methods}

Three plants of each cultivar were washed, the leaves removed, and apical meristems excised under a binocular microscope. The meristems were first fixed in a FAA solution1:1:18 (by volume) mixture of formalin, acetic acid, and 70\% ethanol-for $24 \mathrm{~h}$, then dehydrated using sequential ethanol concentrations of $70 \%, 80 \%, 90 \%, 95 \%$, and $100 \%$. The samples were kept in $100 \%$ ethanol overnight, dried in a criticalpoint drier using $\mathrm{CO}_{2}$ as the transition fluid, then coated with gold before they were examined in a SEM.

\section{'Purple'-defoliated (Expt. 1)}

Solutions of 0,125 , or $250 \mathrm{mg} \mathrm{GA} /$ liter, at $25 \mathrm{ml} /$ pot, were applied to the medium as a drench on 20 Jan. 1987. The same

Abbreviations: $18 \mathrm{SH}, 18 \mathrm{~h}$ of high light treatment; $18 \mathrm{SL}, 18 \mathrm{~h}$ of low light treatment; HPS, high pressure sodium; Nat, natural daylight; SEM, scanning electron microscope; VB, visible bud. 
application was repeated 4 days later. Five days after the second application, all plants were defoliated with scissors and moved to cold storage. Plants were held at $4 \pm 1 \mathrm{C}$ without light for $0,2,4$, or 6 weeks. After completing cold treatments, plants were moved to the greenhouse for photoperiod and irradiance treatments.

Three light treatments were used: 1) 18-h photoperiod with $10 \pm 2 \mathrm{~mol} \cdot \mathrm{m}^{-2} \cdot \mathrm{s}^{-1}$ from $400-\mathrm{W}$ HPS lamps plus natural daylight (18 SL); 2) 18-h photoperiod with $250 \pm 20$ $\mu \mathrm{mol} \cdot \mathrm{m}^{-2} \cdot \mathrm{s}^{-1} 1$ from HPS plus Nat (18 SH); and 3) Nat. The light treatments began at the end of cold treatments.

A randomized complete block (RCB) design was used with a split-split plot arrangement of treatments. $\mathrm{GA}_{3}$, cold, and light treatments were analyzed as main plot, split plot, and split-split plot, respectively. Each treatment had four replications consisting of two plants each. Each replication was placed in a separate but adjacent greenhouse within the same range. Analysis of variance, regression, and Duncan's multiple range test were used in data analysis (Little and Hills, 1972).

\section{'Purple'-foliated (Expt. 2)}

Except for the absence of cold treatments, foliated plants had the same $\mathrm{GA}_{3}$ and light treatments as described in Expt. 1. The light treatments started 29 Jan. 1987. Each treatment had four replications consisting of two plants each.

A RCB design was used with a split plot, with $\mathrm{GA}_{3}$ and light treatments as the main and split plots, respectively. Data analyses were the same as in Expt. 1.

\section{'Dove'-defoliated (Expt. 3)}

Solutions of 0,50 , or $125 \mathrm{mg} \mathrm{GA}_{3} /$ liter with three drops of Tween 20 at $5 \mathrm{ml} /$ plant were sprayed on the foliage on 20 and 24 Jan. 1987. Five days after the second $\mathrm{GA}_{3}$ spray, all plants were defoliated with scissors and moved to cold storage. Plants received the same cold and light treatments as plants in Expt. 1 and the number of treatments, and data analyses also were the same.

\section{'Dove'-foliated (Expt. 4)}

Foliated plants were used that received the same $\mathrm{GA}_{3}$ and light treatments as described in Expt. 3. Experimental design, number of treatments, and data analyses were the same as for Expt. 2.

\section{Results}

\section{SEM studies}

SEM examinations indicated that untreated plants of both cultivars initiated flower buds 4 months after sowing, when they had 13 to 14 leaves. All plants sampled had reached either early stages (Fig. 1), or late stages (Fig. 2) of flower initiation by 10 Dec. 1987. Thus, cold treatment was not necessary for flower initiation for 'Purple' or 'Dove'.

\section{'Purple'-defoliated}

Light effects. Nat plants $(29.4 \mathrm{~cm}$ tall) were significantly shorter than those with $18 \mathrm{SH}$ or $18 \mathrm{SL}$ (32.1 or $31.7 \mathrm{~cm}$ tall, respectively). High light treatment significantly reduced days to anthesis, from 50.3 for Nat plants to 44.3 for 18 SL to 36.6 for $18 \mathrm{SH}$. High light treatment significantly increased the number

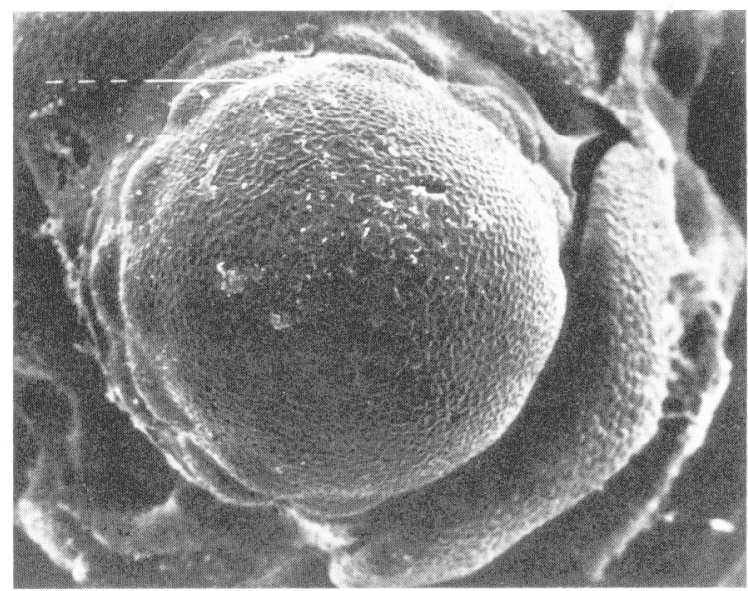

Fig. 1. Apical meristem of Aquilegia $\times$ hybrida 'Purple' showing early stage of flower bud initiation with the protuberances around the lower portion being primordia of sepals and petals. The last bar represents $100 \mu \quad \mathrm{m}$. Magnification $\times 119$.

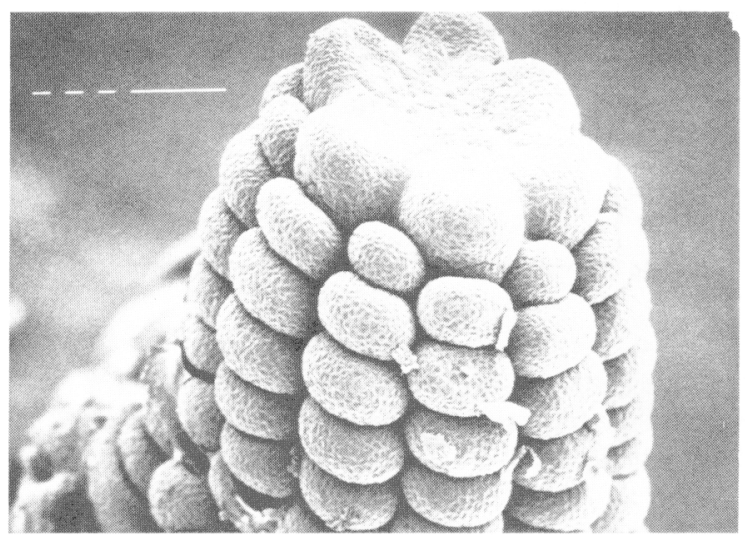

Fig. 2. Apical meristem of Aquilegia $\times$ hybrida 'Purple' showing later of flower bud initiation with the protuberances around the lower portion being primordia of sepals and petals and around the upper portion being primordia of stamens and the top flat one being pistil. The last bar represents $100 \mu \mathrm{m}$. Magnification $\times 99$.

of flowers per plant, from 7.8 for Nat to 12.1 for 18 SL to 16.4 for $18 \mathrm{SH}$ plants.

Cold effects. Cold treatments did not affect the number of days to anthesis under any light conditions but did reduce the number of flowers linearly. Plants that had 0,2 , 4, or 6 weeks of cold treatment had $15.7,14.6,11.1$, or 7.8 flowers per plant, respectively.

$G A_{3}$ and light interactions. There was a significant interaction between $\mathrm{GA}_{3}$ and light levels on days to anthesis. $\mathrm{GA}_{3}$ application of $250 \mathrm{mg}^{-1}$ ler $^{-1}$ reduced the number of days to anthesis under any light conditions. However, the reduction was $25 \%$ under Nat and $20 \%$ and $12 \%$ under 18 SL or $18 \mathrm{SH}$, respectively. With $18 \mathrm{SH}, \mathrm{GA}_{3}$ effects were linear, and with $18 \mathrm{SL}$ or Nat the effects were linearly and quadratically significant (Fig. 3).

$\mathrm{GA}_{3}$ and cold interactions. With 0 or 2 weeks of cold treatments, $\mathrm{GA}_{3}$ application reduced days to VB linearly while with 4 or 6 weeks of cold treatment, $\mathrm{GA}_{3}$ application had linear and quadratic effects (Fig. 4). With 4 or 6 weeks of cold treatments, $\mathrm{GA}_{3}$ applications of 125 and $250 \mathrm{mg}$ liter-'produced virtually the same results. With $125 \mathrm{mg} \mathrm{GA}_{3} /$ liter, cold treatment had 


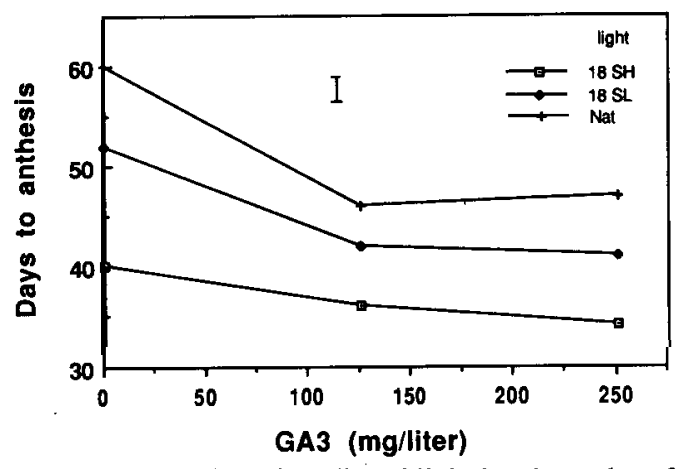

Fig. 3. Effects of $\mathrm{GA}_{3}\left(\mathrm{mg} \cdot \mathrm{liter}^{-1}\right)$ and light levels on days from light treatment to anthesis for defoliated 'Purple' plants. Vertical bars represent LSD at $P=0.05$. $18 \mathrm{SH}$ : 18 -h photoperiod with 250 $\mu \mathrm{mol} \cdot \mathrm{m}^{-2} \cdot \mathrm{s}^{-1}$ from $400-\mathrm{W}$ HPS lamps plus natural sunlight, $18 \mathrm{SL}$ 18-h photoperiod with $10 \mu \mathrm{mol} \cdot \mathrm{m}^{-2} \cdot \mathrm{s}^{-1}$ from HPS plus natural sunlight, Nat: natural daylight.

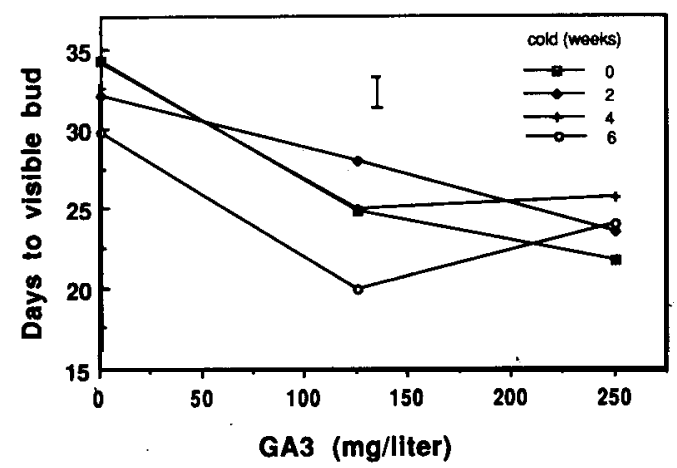

Fig. 4. Effects of $\mathrm{GA}_{3}$ (mg-liter ${ }^{-1}$ ) and cold treatment (weeks) on days from light treatment to VB for defoliated 'Purple' plants. Vertical bars represent LSD at $P=0.05$.

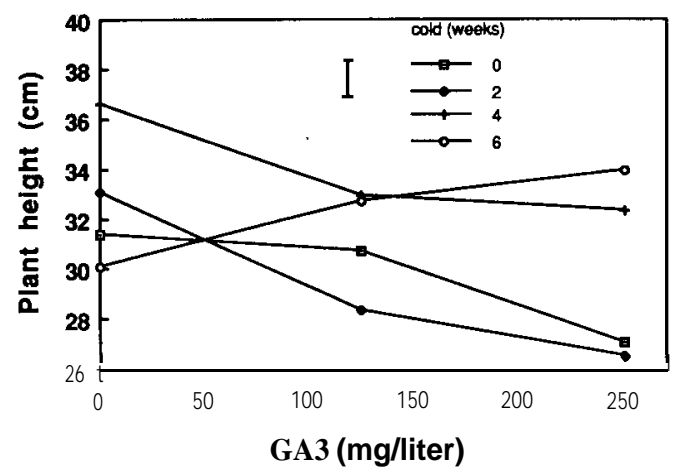

Fig. 5. Effects of $\mathrm{GA}_{3}\left(\mathrm{mgliter}^{-1}\right)$ and cold treatment (weeks) on plant height $(\mathrm{cm})$ for defoliated 'Purple' plants. Vertical bars represent $\mathrm{LSD}$ at $\mathrm{P}=0.05$.

linear and cubic effects on days to VB, while with 0 or $250 \mathrm{mg}$ $\mathrm{GA}_{3} /$ liter cold treatments were not effective.

The height of plants with 0,2 , and 4 weeks of cold treatments decreased linearly as the concentration of $\mathrm{GA}_{3}$ treatment increased from 0 to $250 \mathrm{mg} \cdot$ liter $^{-1}$, while the height of plants with 6 weeks of cold treatment increased as the concentration of $\mathrm{GA}_{3}$ increased from 0 to $250 \mathrm{mg} \cdot$ liter $^{-1}$ (Fig. 5).

Light and cold interactions. With Nat or $18 \mathrm{SH}$, cold treatments decreased inflorescence number linearly or linearly and cubically, respectively, while with $18 \mathrm{SL}$, cold treatment was not effective (Fig. 6). With no cold treatment, light treatments did not significantly affect the number of in florescences, while

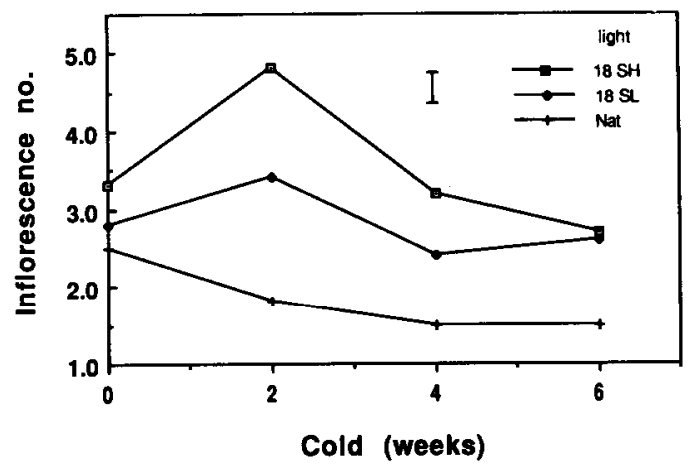

Fig. 6. Effects of light level and cold treatment (weeks) on number of inflorescences for defoliated 'Purple' plants. Vertical bars represent LSD at $P=0.05$. $18 \mathrm{SH}$ : 18 -h photoperiod with 250 $\mu \mathrm{mol} \cdot \mathrm{m}^{-2} \cdot \mathrm{s}^{-1}$ from $400-\mathrm{W}$ HPS lamps plus natural sunlight, $18 \mathrm{SL}$ : 18 -h photoperiod with $10 \mu \mathrm{mol} \cdot \mathrm{m}^{-2} \cdot \mathrm{s}^{-1}$ from HPS plus natural sunlight, Nat: natural daylight.

Tabie 1. Efffects of ilight treatments on number of days from the first day of light treatment to appearance of a VB and anthesis, plant height, number of inflorescences, and flowers per plant in foliated Aquilegia 'Purple'.

\begin{tabular}{lccccc}
\hline \hline Light $^{z}$ & $\begin{array}{c}\text { Days to } \\
\text { VB }\end{array}$ & $\begin{array}{c}\text { Days to } \\
\text { anthesis }\end{array}$ & $\begin{array}{c}\text { Plant ht } \\
(\mathrm{cm})\end{array}$ & $\begin{array}{c}\text { Inflorescences } \\
\text { (no.) }\end{array}$ & $\begin{array}{c}\text { Flowers/ } \\
\text { plant }\end{array}$ \\
\hline $18 \mathrm{SH}$ & $19.7 \mathrm{~b}^{\mathrm{y}}$ & $33.3 \mathrm{~b}$ & $30.0 \mathrm{ab}$ & $4.3 \mathrm{a}$ & $20.8 \mathrm{a}$ \\
$18 \mathrm{SL}$ & $32.0 \mathrm{a}$ & $50.1 \mathrm{a}$ & $32.6 \mathrm{a}$ & $2.3 \mathrm{~b}$ & $13.1 \mathrm{~b}$ \\
Nat & $33.4 \mathrm{a}$ & $47.1 \mathrm{a}$ & $27.0 \mathrm{~b}$ & $2.5 \mathrm{~b}$ & $16.5 \mathrm{ab}$ \\
\hline
\end{tabular}

${ }^{2} 18 \mathrm{SH}: 18$-h photoperiod with $250 \mu \mathrm{mol} \cdot \mathrm{m}^{-2} \cdot \mathrm{s}^{-1}$ from $400-\mathrm{W}$ high pressure sodium lamps (HPS) plus Nat, $18 \mathrm{SL}$ : 18-h photoperiod with $10 \mu \mathrm{mol} \cdot \mathrm{m}^{-2} \cdot \mathrm{s}^{-1}$ from HPS plus Nat; Nat: natural daylight.

yMean separation within columns by Duncan's multiple range test, $P=0.05$.

with 2, 4, or 6 weeks of cold treatment, Nat plants had fewer inflorescences than $18 \mathrm{SH}$ or $18 \mathrm{SL}$ plants (Fig. 6).

\section{'Purple'-foliated}

Light eflects. Plants with $18 \mathrm{SH}$ reached VB or anthesis significantly earlier than those exposed to $18 \mathrm{SL}$ or Nat (Table 1). The 18 SL plants were significantly taller than Nat plants, while the $18 \mathrm{SH}$ plants were not different from either $18 \mathrm{SL}$ or Nat plants. The $18 \mathrm{SH}$ plants had more inflorescences per plant than the $18 \mathrm{SL}$ or Nat plants. The $18 \mathrm{SH}$ plants had more flowers per plant than the 18 SL plants, while Nat plants were not different from either $18 \mathrm{SH}$ or $18 \mathrm{SL}$ plants.

$\mathrm{GA}_{3}$ and light interactions. With $18 \mathrm{SH}, \mathrm{GA}_{3}$ reduced days to VB linearly $\left(22,21\right.$, or 16 days for 0,125 , or $250 \mathrm{mg} \cdot \mathrm{liter}^{-1}$, respectively), while with $18 \mathrm{SL}, \mathrm{GA}_{3}$ effects were not significant. The reduction in days to VB by $\mathrm{GA}_{3}$ treatments was linearly and quadratically significant with Nat $(68,29$, or 29 days for 0,125 , or $250 \mathrm{mg} \cdot \mathrm{liter}^{-1}$, respectively). Only $25 \%$ of the plants without $\mathrm{GA}_{3}$ but $100 \%$ of the plants with both $\mathrm{GA}_{3}$ treatments reached VB. With Nat, none of the plants without $\mathrm{GA}_{3}$ and $75 \%$ or $100 \%$ of the plants with $\mathrm{GA}_{3}$ at 125 or $250 \mathrm{mg} \cdot \mathrm{liter}^{-1}$ reached anthesis by the time the experiment was terminated. GAS had no significant effects on the number of days to anthesis, plant height, or number of inflorescences and flowers.

\section{'Dove'-defoliated}

$G A_{3}$ effects. $\mathrm{G} \mathrm{A}_{3}$ application reduced plant height linearly; plants treated with 0,50 , or $125 \mathrm{mg} \cdot$ liter $^{-1}$ were 23,22 , or 20 $\mathrm{cm}$ tall, respectively. 
Light effects. Supplemental lighting increased the number of inflorescences per plant significantly. Plants with $18 \mathrm{SH}, 18$ SL, or Nat had 4.8, 3.4, or 2.5 inflorescences per plant, respectively.

Cold effects. Cold treatments had linear effects on the number of inflorescences. The number of inflorescences per plant. was $3.9,4.0,3.6$, or 3.0 for plants with 0,2 , 4, or 6 weeks of cold treatment. Cold treatments did not have significant effects on the number of days to anthesis.

$\mathrm{GA}_{3}$ and light interactions. GAS reduced number of days to VB or anthesis regardless of light treatments. The higher the GAS concentration, the shorter time plants needed to reach VB or anthesis (Figs. 7 and 8). However, the reduction by $\mathrm{GA}_{3}$ was greater from 0 to $50 \mathrm{mg} \cdot$ liter $^{-1}$ than from 50 to $125 \mathrm{mg} \cdot$ liter $^{-1}$. In addition, the reduction was greater with Nat than with 18 SH.

Light and cold interactions. Plants exposed to $18 \mathrm{SH}$ reached VB earlier than those exposed to $18 \mathrm{SL}$ or Nat, regardless of cold treatments. The effects of cold treatments on VB were not consistent with light levels (Fig. 9). With $18 \mathrm{SH}$, the cold treatments did not have significant effects on VB; with 18 SL, prolonged cold treatments did not have significant effects compared with 2 weeks, but the 2 -week cold treatment reduced days to VB; with Nat, longer cold treatments were more effective.

The $18 \mathrm{SH}$ plants had more flowers per plant than those with

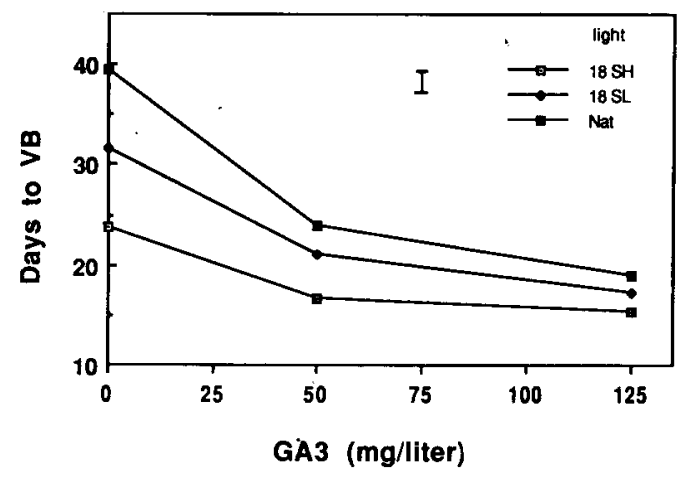

Fig. 7. Effects of $\mathrm{GA}_{3}\left(\mathrm{mg} \cdot \mathrm{liter}^{-1}\right)$ and light levels on days from light treatment to VB for defoliated 'Dove' plants. Vertical bars represent LSD at $P=0.05 .18 \mathrm{SH}: 18$-h photoperiod with $250 \mu \mathrm{mol} \cdot \mathrm{m}^{-2} \cdot \mathrm{s}^{-1}$ from 400-W HPS lamps plus natural sunlight, 18 SL: 18-h photoperiod with $10 \mu \mathrm{mol} \cdot \mathrm{m}^{-2} \cdot \mathrm{s}^{-1}$ from HPS plus natural sunlight, Nat: natural daylight.

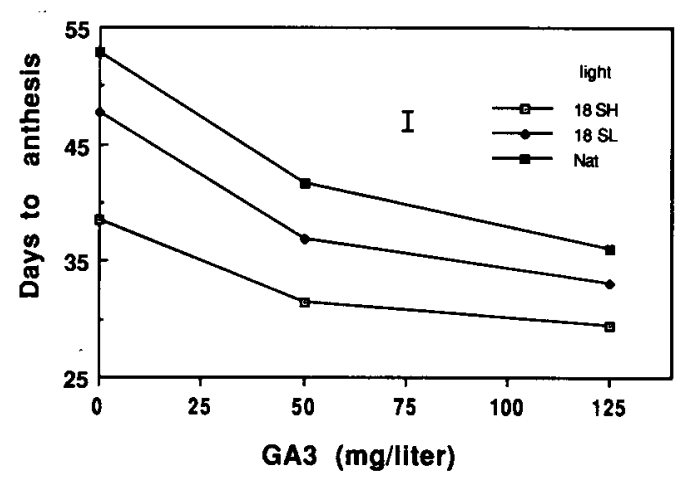

Fig. 8. Effects of $\mathrm{GA}_{3}\left(\mathrm{mg} \cdot \mathrm{liter}^{-1}\right)$ and light levels on days from light treatment to anthesis for defoliated 'Dove' plants. Vertical bars represent LSD at $P=0.05$. $18 \mathrm{SH}: 18$-h photoperiod with 250 $\mu \mathrm{mol} \cdot \mathrm{m}^{-2} \cdot \mathrm{s}^{-1}$ from 400 -W HPS lamps plus natural sunlight, $18 \mathrm{SL}$ : 18 -h photoperiod with $10 \mu \mathrm{mol} \cdot \mathrm{m}^{-2} \cdot \mathrm{s}^{-1}$ from HPS plus natural sunlight, Nat: natural daylight.
18 SL or Nat, regardless of cold treatments. With $18 \mathrm{SH}$, the number of flowers per plant decreased linearly as cold treatment increased from 0 to 6 weeks, while, with $18 \mathrm{SL}$ and Nat, cold treatments did not have a significant effect on the number of flowers per plant (Fig. 10).

The $18 \mathrm{SH}$ and $18 \mathrm{SL}$ treatments increased plant height significantly only on plants without cold treatment (Fig. 11). With $18 \mathrm{SL}$ and Nat, cold treatments increased plant height linearly, while with $18 \mathrm{SH}$, cold treatments did not have significant effects on plant height (Fig. 11).

\section{'Dove'-foliated}

Light effects. The $18 \mathrm{SH}$ treatment reduced number of days to $\mathrm{VB}$ and anthesis compared with $18 \mathrm{SL}$ or Nat, regardless of $\mathrm{GA}_{3}$ treatments, while the latter two were not significantly different (Table 2). Plants treated with $18 \mathrm{SH}$ or $18 \mathrm{SL}$ were taller than control plants. Plants under $18 \mathrm{SH}$ had more than twice as many flowers as plants under Nat. However, no significant difference existed between 18 SL and control plants (Table 2).

$\mathrm{GA}_{3}$ effects. GAS application reduced time to anthesis and the effects were linearly and quadratically significant $(43,38$, or 37 days for 0,50 , or $125 \mathrm{mg} \cdot$ liter $^{-1}$ plants, respectively). $\mathrm{GA}_{3}$

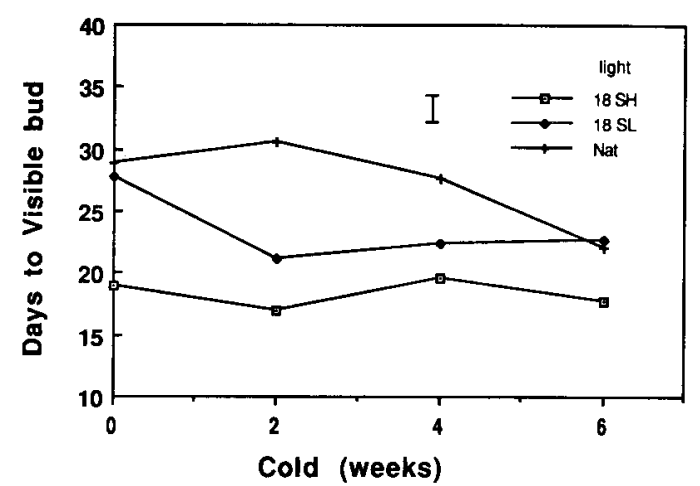

Fig. 9. Effects of cold treatment (weeks) and light levels on days from light treatment to VB for defoliated 'Dove' plants. Vertical bars represent LSD at $P=0.05 .18 \mathrm{SH}$ : 18 -h photoperiod with 250 $\mu \mathrm{mol} \cdot \mathrm{m}^{-2} \cdot \mathrm{s}^{-1}$ from $400-\mathrm{W}$ HPS lamps plus natural sunlight, $18 \mathrm{SL}$ : 18 -h photoperiod with $10 \mu \mathrm{mol} \cdot \mathrm{m}^{-2} \cdot \mathrm{s}^{-1}$ from HPS plus natural sunlight, Nat: natural daylight.

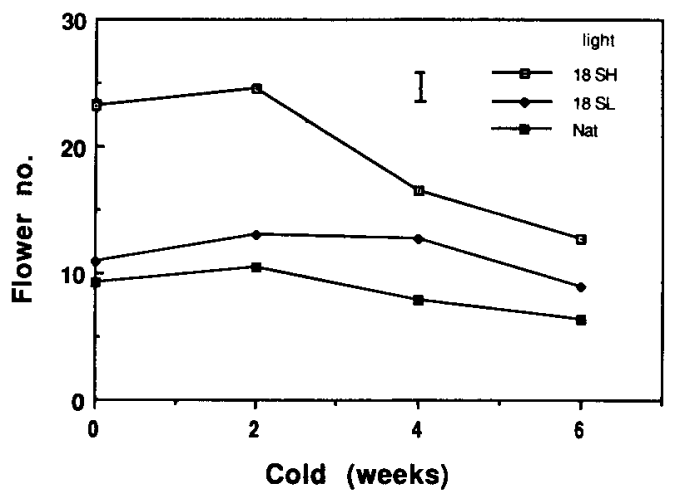

Fig. 10. Effects of cold treatment (weeks) and light levels on number of flowers per plant for defoliated 'Dove' plants. Vertical bars represent LSD at $P=0.05$. $18 \mathrm{SH}: 18$ h photoperiod with 250 $\mu \mathrm{mol} \cdot \mathrm{m}^{-2} \cdot \mathrm{s}^{-1}$ from $400-\mathrm{W}$ HPS lamps plus natural sunlight, $18 \mathrm{SL}$ : 18-h photoperiod with $10 \mu \mathrm{mol} \cdot \mathrm{m}^{-2} \cdot \mathrm{s}^{-1}$ from HPS plus natural sunlight, Nat: natural daylight. 


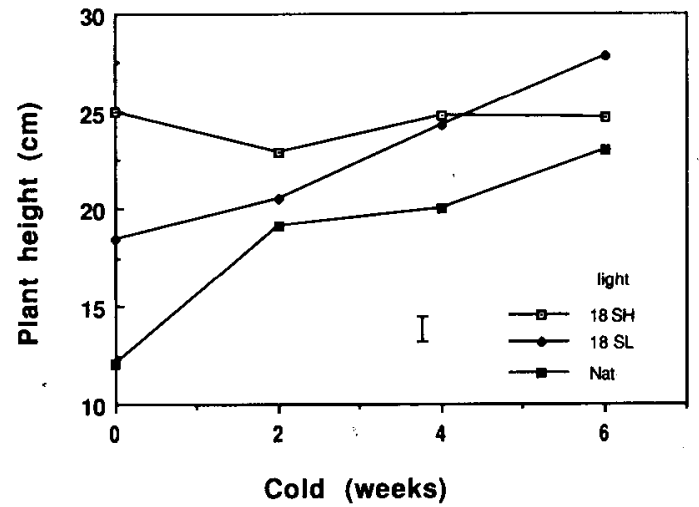

Fig. 11. Effects of cold treatment (weeks) and light levels on plant height $(\mathrm{cm})$ for defoliated 'Dove' plants. Vertical bars represent LSD at $P=0.05 .18 \mathrm{SH}: 18$-h photoperiod with $250 \mu \mathrm{mol} \cdot \mathrm{m}^{-2} \cdot \mathrm{s}^{-1}$ from 400-W HPS lamps plus natural sunlight, 18 SL: 18 -h photoperiod with $10 \mu \mathrm{mol} \cdot \mathrm{m}^{-2} \cdot \mathrm{s}^{-1}$ from HPS plus natural sunlight, Nat: natural daylight.

Table 2. Effects of light treatments on number of days from the first day of light treatment to appearance of a VB and anthesis; plant height, number of inflorescences, and flowers per plant in foliated Aquilegia 'Dove'.

\begin{tabular}{lccccc}
\hline \hline Light & $\begin{array}{c}\text { Days to } \\
\text { VB }\end{array}$ & $\begin{array}{c}\text { Days to } \\
\text { anthesis }\end{array}$ & $\begin{array}{c}\text { Plant ht } \\
\text { (cm) }\end{array}$ & $\begin{array}{c}\text { Inflorescences } \\
\text { (no.) }\end{array}$ & $\begin{array}{c}\text { Flowers/ } \\
\text { plant }\end{array}$ \\
\hline $18 \mathrm{SH}$ & $19.6 \mathrm{~b}^{\mathrm{y}}$ & $33.1 \mathrm{~b}$ & $22.4 \mathrm{a}$ & $5.0 \mathrm{a}$ & $23.0 \mathrm{a}$ \\
$18 \mathrm{SL}$ & $26.0 \cdot \mathrm{a}$ & $43.7 \mathrm{a}$ & $21.0 \mathrm{a}$ & $3.6 \mathrm{~b}$ & $14.9 \mathrm{~b}$ \\
Nat & $26.2 \mathrm{a}$ & $40.5 \mathrm{a}$ & $15.0 \mathrm{~b}$ & $2.3 \mathrm{c}$ & $10.3 \mathrm{~b}$ \\
\hline
\end{tabular}

${ }^{2} 18 \mathrm{SH}$; 18-h photoperiod with $250 \mu \mathrm{mol} \cdot \mathrm{m}^{-2} \cdot \mathrm{s}^{-1}$ from $400-\mathrm{W}$ high pressure sodium lamps (HPS) plus Nat, $18 \mathrm{SL}$ : 18-h photoperiod with $10 \mu \mathrm{mol} \cdot \mathrm{m}^{-2} \cdot \mathrm{s}^{-1}$ from HPS plus Nat; Nat: natural daylight.

yMean separation within columns by Duncan's multiple range test, $P=0.05$.

had no significant effects on plant height or number of inflorescences and flowers per plant.

$G_{3}$ and light interactions. There were significant interactions between GAS and light treatments on number of days to VB. With Nat, GA 3 reduced days to VB (linearly and quadratically significant; 53,23 , or 23 days for 0,50 , or $125 \mathrm{mg} \cdot$ liter $^{-1}$ plants, respectively). With $18 \mathrm{SH}, \mathrm{GA}_{3}$ effects were linear (24, 18 , or 17 days for 0,50 , or $125 \mathrm{mg} \cdot \operatorname{liter}^{-1}$ plants, respectively). With 18 SL GAS effects were also linear $(31,25$, or 22 days for 0,50, or $125 \mathrm{mg} \cdot$ liter $^{-1}$, respectively).

\section{Discussion}

$G A_{3}$ treatments. Different concentrations and application methods of GAS were used based on the assumption that the two cultivars were genetically similar enough to respond similarly to $\mathrm{GA}_{3}$ application. The number of days to anthesis was reduced by GAS application regardless of light and cold treatments throughout this study. The reduction was greatest for plants, under Nat. This is in agreement with the findings by Lyons and Widmer (1983) that $\mathrm{GA}_{3}$ accelerated the rate of growth and development of Cyclamen persicum (Mill). Some differences existed among experiments reflecting the differences between application methods and cultivars. The question of residual $\mathrm{GA}_{3}$ effects, and how $\mathrm{GA}_{3}$ application in later stages of plant growth affects flower development requires more experimentation.

$\mathrm{GA}_{3}$ significantly affected plant height of defoliated plants but not of foliated plants. Contrary to the original hypothesis that $\mathrm{GA}_{3}$ would increase plant height (De Hertogh and Blakely, 1972; Post, 1942; Shedron and Weiler, 1982), in some cases $\mathrm{GA}_{3}$-treated plants were shorter than controls (Fig. 5), perhaps because $\mathrm{GA}_{3}$ shortened the interval from treatment to anthesis, and, consequently, the time for inflorescences to elongate was also reduced.

Light treatments. Consistent with the findings by Poesch and Laurie (1932), Post (1942), and Hughes and Cockshull (1969) on other crops, throughout the four experiments a high level of irradiance $(18 \mathrm{SH})$ greatly reduced number of days to anthesis compared with $18 \mathrm{SL}$ and Nat, regardless of $\mathrm{GA}_{3}$ and cold treatments (Tables 1 and 2; Figs. 3, 7, and 9). The 18 SL treatment was not as effective as $18 \mathrm{SH}$, indicating that it was probably the total irradiance rather than long photoperiod that hastened flower development. The effects of $18 \mathrm{SH}$ might be due partly to higher leaf temperatures (not measured) caused by higher levels of irradiance, which in turn accelerated the rate of development.

As with chrysanthemums [Dendranthema $\times$ grandiflorum (Ramat.) Kitamura] (Hicklenton and McRae, 1984), Alstroemenia (Lin and Molnar, 1983), and roses (Carpenter and Anderson, 1971), long photoperiod with a high level of irradiance (18 SH) significantly increased the number of flowers per plant throughout the study except for Expt. 2, where $18 \mathrm{SH}$ plants did not have more flowers per plant than Nat plants (Tables 1 and 2; Fig. 11).

Supplementary lighting (photosynthetically active radiation) with extended daylength would benefit commercial production of Aquilegia plants by reducing time to anthesis and increasing the number of flowers, especially in winter when natural light levels are low.

Cold treatments. Flower bud initiation occurred without cold treatments in this study, indicating that these two Aquilegia cultivars do not require chilling for flower initiation. This is in agreement with a previous report on Aquilegia $\times$ hybrida cultivars (White et al., 1990). Additional research is needed to determine whether these Aquilegia cultivars could initiate flower buds earlier if they are exposed to low temperatures at an earlier stage of development.

Cold treatments decreased the number of developed flowers in all 'Purple' and some defoliated 'Dove' plants (Fig. 11), probably because the flower buds were initiated before cold treatments and because plants used up more of their stored carbohydrates during extended cold storage. As a result, more flower buds would abort due to an increasing deficiency of stored food. Therefore, cold treatments are not recommended for these cultivars. The decrease in the number of flowers per plant, time in cold storage, and cost of facilities for cold treatment must be taken into consideration in commercial production if cold treatments are to be used.

\section{Literature Cited}

Carpenter, W.J. and G.A. Anderson. 1971. High intensity supplementary lighting increases yields of greenhouse roses. J. Amer. Soc. Hort. Sci. 97:331-334.

De Hertogh, A.A. and N. Blakely. 1972. Influence of gibberellins A3 and A4 +7 on development of forced Lilium longiflorum Thunb. cv. Ace. J. Amer. Soc. Hort. Sci. 97:320-323.

Hicklenton, P.R. and K.B. McRae. 1984. Vegetative growth and flowering of pot chrysanthemums in response to supplemental HPS radiation and split-night temperatures. J. Amer. Soc. Hort. Sci. 109:3033. 
Hughes, A.P. and K.E. Cockshull. 1969. Cyclic night-breaks can advance flowering. Greenhouse Grower 71:601.

Lin, W.C. and J.M. Molnar. 1983. Effect of photoperiod and high intensity supplementary lighting on flowering of Alstroemenia 'Orchid' and 'Regina'. J. Amer. Soc. Hort. Sci. 108:914-917.

Little, T.M. and F.J. Hills. 1972. Statistical methods in agricultural research. Univ. of Calif., Davis. p. 67-84.

Lyons, R.E. and R.E. Widmer. 1983. Effects of GA3 and NAA on leaf lamina unfolding and flowering of Cyclamen persicum. J. Amer. Soc. Hort. Sci. 108:759-763.
Poesch, G.H. and A. Laurie. 1932. Photoperiodism. Ohio Agr. Expt. Sta. Bul. 512:42.

Post, K. 1942. Daylength, temperature and flowering of florist crops. Cornell Univ. Expt. Sta. Bul. 787:25.

Shedron, K.G. and T.C. Weiler. 1982. Regulation of growth and flowering in Aquilegia $\times$ hybrids Sims. J. Amer. Soc. Hort. Sci. 107:878882.

White, J.W., H. Chen, X. Zhang, D.J. Beattie, and H. Grossman. 1990. Floral initiation and development in Aquilegia. HortScience 25:294-296. 